\title{
The Challenge of Change for the School Supervisor Orientation Against the Impact of Industrial Revolution 4.0
}

\author{
Aceng Muhtaram Mirfani \\ Departement of Educational Management \\ Universitas Pendidikan Indonesia, Indonesia \\ am_mirfani@upi.edu
}

\begin{abstract}
The school supervisor has a strategic role in efforts to enhance the educational qualities. The implementation of schooling in the industrial revolution era 4.0 requires various adjustments. Likewise, the school supervisor competencies need to be continuously updated along with the demands for changes in their strategic roles. This paper tries to explain the various challenges of changes in supervisory orientation in relation to the demands of educational qualities in the industrial revolution era 4.0, with a background case illustration in Indonesia oriented towards entering the era of education 4.0.
\end{abstract}

Keywords: change, industrial revolution era 4.0, school supervisor

\section{INTRODUCTION}

The competence of school supervisors in both managerial and academic dimensions is being faced with new challenges as a result of the impact of the era of industrial revolution 4.0. The first way the school supervisors conduct academic supervision is that middle teachers have different needs than the previous period. The teaching and learning situation needed also changes. Likewise, the first goal in conducting managerial supervision, namely the principal, is required to have a new orientation.

Competence in managing change is closely related to institutional leadership roles [15]; [7] which is very much in line with the contemporary role in the era of industrial revolution 4.0, namely the achievement of global leadership [16]. Behind all that, there is essentially a demand for an increase in the quality of education in a more core perspective. Then the need to strengthen competencies to manage change towards a community of effective learning educators is a prerequisite for topping up the new challenges.

On the other hand, the determination of peculiarities to adapt the modernization strategy of the socio-economic system [23] and the determination of the main problem of the formation of Industry 4.0 in the modern world is a challenge for the compilation of realistic estimates and modernization. What is very important is the perspective of solving this problem in the interests of the establishment of a fast Industry 4.0 and the achievement of global leadership. Furthermore, the success of integration into digital ecosystems is very much needed [23]. In short, a change in supervisory orientation is needed for school supervisors in entering the Education 4.0 era [19].

Among the challenges for school's supervisors are that they must be oriented not only to the demands of skills in the 21 st century but also to consider learning management in the aspects of Social \& Virtual Learning [19]. In the education era 4.0, at least, six skills must be mastered [10]. The six skills are critical thinking and consideration; make use of innovative knowledge and information; solving complex, multidisciplinary and open problems; communicate and collaborate; creativity and entrepreneurial thinking; global communication, global thinking. Related to social \& virtual learning there is a strong tendency among educators in mastering technological knowledge more left behind by students [1]. Indeed, in some circles, it is still more pleased with working conditions that are close to the era of industry 3.0 [17]

\section{METHOD}

The study of thinking about information and communication technology and the era of the educational revolution, which addresses the challenges of its application, was developed using the "comparative" and "advocacy-discovery" methods. This is done by considering the problems of the challenges that require basic foundations and values in addition to disclosing the value of future people's lives, as well as fulfilling their conformity with the concept of global leadership. A comparative method is carried out for the implementation of the target program and its realization.

While the second method is adapted from a method known as exploration attributes [5]. Exploration attributes are a very common method of acquiring knowledge, valid for all types and not limited to mathematical questions. What we expect from this method helps with classification procedures. The basic task is very simple: for a specific list of attributes, we find all combinations of attributes found. The original concept must be simplified as possible, avoided everything needed and allowed the computer to do technical. In this case, the application is not a computer, but a consideration of the mind.

\section{RESUlt AND Discussion}

Guidance of academic supervision by school supervisors to teachers is important directed at the demands of learning that are in line with the era of industrial revolution 4.0. Teachers are being faced with learning services for generation $Z$. In which case "Generation Z's brain is connected with sophisticated, complex visual imaging, and as a result, the part of the 
brain responsible for visual abilities is far more developed, making forms of visual learning more effective "[21].

Guiding managerial supervision of principals is importantly directed at the role of institutional leadership. That the responsibility of establishing the organization's mission, shaping its culture, and protecting and maintaining institutional integrity are the main roles of institutional leadership. Therefore, it becomes increasingly important for school supervisors to reorient the role of institutional leadership of principals in the embodiment of the concept of school-based management [2]. Schoolbased management is intended as a concept designed to improve the quality of education. So, it is relevant to the functions and roles of school supervisors. School-based management, among others, is defined as a process in which decisions that directly affect the school are transferred from the head office to the school level. The principal is a key figure in all school decision making. So, the target of the acceptance of managerial supervision of school supervisors should be directed at the role of the principal as a true school administrator.

School administrators are responsible for running school management. In this case, the school supervisor is challenged to direct the development of the quality management of the school. If the purpose of applying the concept of school-based management can be perceived to be identical with realizing School Good-Governance, then this becomes the area of the school supervisor's role in the dimensions of managerial supervision. The successful administrator is the one who can manifest an advanced, stable, and harmonious school.

In other words, the main indicators of good school governance are schools that are effective, efficient and quality (transparent and accountable). If the efficiency and stability of the school system are produced by managerial processes, the quality and harmony of the school system are generated by the process of organizational communication, the effectiveness and progress of the school system is the result of the institutional leadership process. Institutional leadership also means change leadership, the leadership of principals that deliver on the resilience of school institutions.

In the Indonesian national education system, the principal has been placed in the position and task. However, concerning some expectations to be able to play a role as the responsibility in question, it is still constrained if the professionalism of the school principal has not grown well. Understandably this happens because the school supervisor has not been present properly. Not only management factors that generally occupy a weak position in the constellation of school education in Indonesia, but there is also a strong tendency for Education administrators and their supervisors, especially school principals and supervisors, to be faced with conditions that make them powerless to make changes constructive in order to improve school performance led or guided. So, the presence of school supervisors became increasingly urgent as a breakthrough in the issue and facilitation of the acceleration of renewal. Specially to lead in the era of industrial revolution 4.0 which is faced with the demands of four novelty, namely: new mental models, new learning styles, several new abilities, and many new structures [10]. The demands of a new mental model are related to thinking and feeling which includes: reading that is scanned, image-oriented, and "according to virtually". The demands of new learning styles are related to learning which includes game-based learning and is used for quick feedback. The demands of new capabilities related to work habits include multi-delay, non-linear approaches, and technology enthusiasts. The demands of the new structure are related to social life which includes networking, community-oriented, not only bound to one company, one field, etc.

The challenge for school officials in facilitating the reform movement is a major weakness of the principal's institutional leadership role as an administrator only likes to maintain existing regulations [18]. They can only appear as school managers. In such conditions, it is very difficult to expect the change of leadership of the head of the school to appear as it should play a role in the era of industry 4.0 revolution.

Because in reality most of them feel as careers and assume that change should be doubted. Even though education is running on the scene of changes in the global environment that is running faster. In the meantime, how the school supervisors make it as a point of professional awareness to play an active role optimally. Especially amid the inability of the institution assigned by the government (Institute for Development and Empowerment of Principals) to complete the certification of school principals. After 8 years (2011 until 2018) there is only about $11 \%$ certified [16].

The supervisors should improve leadership competencies renewed by the principal directed at the importance of the resilience of school institutions as global leaders. Discussing the resilience of an institution's school cannot be separated from the challenges, pressures, and demands of the school environment concerned. All of these things can occur due to changes in the interrelated life order, both those that occur outside the school environment and within the school environment.

Changes in the order of life itself, in general, can occur quickly as a consequence of efforts to modernize the lives of the communities where the schools are located. Especially nowadays, which is considered by experts as an era of globalization that has strong support from the advancement of science and technology, media of communication and information, and transportation. The world is now entering the "super symbolic" civilization [24]. It has even been anticipated to enter the era of the 5.0 community which is characterized by smart personal agents [3]. School supervisors should have understood earlier and mastered the knowledge of it.

Schools that are institutions of people's lives have long been seen as a vehicle intended to enable better learning for students. In connection with that also the school was used as a better place to study. Thus, the school is expected to provide a basis for the possibility of developing the human aspects of students in the optimal direction. By this purpose, it is hoped that in turn, it will have a positive impact on the progress of society, especially those around the school. Therefore, according to the global demands, it is appropriate if the school supervisors establish their guidance in the school perspective to have a very strategic role in the process of nation-building amid global affairs. 
This would have been realized by many parties. But the insights of school supervisors about the purpose of administering schools are not enough just to arrive at general purposes as mentioned above, but he must arrive at what knowledge he should do to make it happen. For this reason, guidance in elaborating goals is differentiated into terms: purpose, mission, and objective [8] need to be harmonized with the main functions of the school. Guidance on important school tasks is directed at four main functions, namely: (1) providing a community distribution mechanism, (2) providing safeguards, (3) presenting teaching basic skills, and (4) introducing scientific disciplines [6]. The initial step for professional school administrators must be knowledge of what the school does is connected with the right mind about what should be done.

The firmness or strengthening of school supervisors concerning the objectives of school administration seems to be increasingly urgent given the reliability of schools, in general, is still questionable. The reason may be that his existence has deviated from what was intended. Sometimes he functions to become a kind of "ivory tower in the middle of a forest" and can even be a "prison" for its inhabitants. He is far from touch and even the owner, the community, and the residents are entangled by routines that are not only boring but very tiring. They are confined by that habit. There is no passion and enthusiasm, let alone the desire to increase efforts so that schools are more advanced along with changes in the environment.

The sharp criticism of the implementation of school education as expressed by Ivan Illich and E. Reimer [20] is related to the matter as mentioned above. The question of the existence of "schooling" even to the thesis that demands a change in the concept of education as a whole. The meaning of such circumstances can be said that schools will tend to be in a crisis of selfhood or weakening institutional resilience. Therefore, joint assessment, especially by school supervisors, is very important considering schools as a system can experience entropy, which is a tendency for disorganization or chaos. The results of the study can be useful to be able to avoid it. And if the situation has indeed happened then the study is expected to find out the opportunities and ways to overcome them. At least the school supervisor will be able to avoid a worse situation.

School supervisors can look closely at the need for change in school education coming from two environments, namely external and internal. Both educational environments share the pressure to change. Response to external environmental stress is a manifestation of the educational adaptation mission in change. While the response to the internal environment is a form of intervention mission and educational competition mission for change.

The dynamism of the development of life that is so fast cannot be denied has given increasingly strong pressure on personal and organizational life. So, in line with the perspective of system theory [15] that if the stronger pressure does not get a harmonious response, automatically the chaos of the system will be unavoidable, entropy will occur. The system equilibrium point is disrupted. If that continues, then, in turn, there will be disorganization, the system is destroyed and even destroyed. The worst situation is certainly not cool. By school supervisors are required to conduct guidance so that there is back pressure in the form of a response that can make the system back to a new equilibrium point.

System equilibrium points that are maintained, in the sense that they are always updated (renewal) and following the amount of pressure received can deliver the system to exist. Thus, the survival of a school depends on the internal ability of the system to put back pressure on the pressure of the external environment of the system. That means what is called "steady-state homeostatic", borrowing the term physics-biology. Thus, it is increasingly clear that school needs change. For school organizations that have been able to learn (learning organization), it will not be too difficult to respond to the demands of these changes [22]. It also means that the orientation of the school supervisor needs to be directed at the growth of the learning organization.

The industrial revolution 4.0 will encourage an increase in the efficiency and productivity of our current lifestyle [4], which leads to an increase in the level of global income; improving the quality of life with higherorder technology; reduction in transportation and communication costs; creation of new products and markets; safer workplaces as hazardous work taken over by robots; health care improvements that lead to longevity.

We can further examine how the dynamics of life relate to the demands of change. The pressure on life today by experts is studied, among others, concerning globalization. Today's globalization is characterized by a variety of very strong innovations in transportation and communication infrastructure and the meeting of government institutions and global regulation to approach universal forms [13]. It can be said that the world is now borderless. And in fact, today's globalization has more influence on personal life, organization, society, and the state than globalization in the previous era. Today's globalization is increasingly loaded with opportunities and challenges. By transformationalists, it is seen as a process that contains internal opposition and countervailing.

The rapid development of information and communication technology (ICT) is increasingly strengthening and even being evidence of the realization of a world without limits. Furthermore, ICT amid globalization has brought fundamental implications by shifting the value of products and services from the physical to digital domains. In "Powershift" [23] it was explained that we are in the era of globalization which, among others, is characterized by "super symbolic" culture. The essence is information that is packaged in digital facilities. In the world of education, the acceleration of ICT progress has led to learning transformation through education. That education has the potential to improve learning outcomes in three ways [9]: (1) facilitate access to content and experts, overcome time, location, and collaboration constraints; (2) personalize educational solutions for students, help educators adjust the teaching process, use software and interactive media that adapt the difficulty level of understanding and speed of each student; (3) aimed at the specific challenges of reducing the efficiency of the world education system. Because of that, the orientation of school supervisors became a necessity to be directly involved in the Digitalization 
Movement. Fostering professional-based ICTs is a new requirement for supervisors.

\section{Conclusion}

School supervisors cannot avoid the pressures of global change and the impact of the industrial revolution 4.0 on education. They are required to reorient their roles in line with the demands for change both in the dynamics of learning and in school governance. First, supervisors must complete their capacity to play a role not just as agents of change, but rather become masters of change [11]. Only present with the strengthening of these roles is likely that in turn the leading education actors in schools, teachers, and principals will be more nurtured in responding to demands due to the industrial revolution 4.0. The challenge of school supervisors is to make global education leaders at the school level.

\section{REFERENCES}

[1] Cilliers, E., J. "The Challenge of Teaching Generation Z". PEOPLE: International Journal of Social Sciences, 3(1), 188-198, 2017.

[2] Daniel L. Duke dan Robert L. Canady, 1991.

[3] Diana Benito-Osorio at.all, "Web 5.0: the future of emotional competences in higher Education, International Network of Business and Management - Glob Bus Perspect” 1:274-287 DOI 10.1007/s40196-013-0016-5, 2013.

[4] Diwan, Parag, Medium, Retrieved 2 July 2019, from https://medium.com/@pdiwan/is-education-4-0-animperative-for-success-of-4th-industrial-revolution50c31451e8a4, 2017.

[5] Ganter, G. Bernhar \& Obiedkov, Sergei, "Conceptual Exploration"; Springer-Verlag Berlin Heidelberg, DOI 10.1007/978-3-662-49291-8. 2016.

[6] Holmes, Mark dan Waynne, Edward A. "Making the School an Effective Community: Belief, Practice and Theory in School Administration", London: The Falmer Press et the blessing of God Almighty. 1989.

[7] Hoy, Wayne K. dan Miskel, Cecil G. "Educational Administration Theory, Research, and Practice"; New York: Random House Inc. .

[8] James A.F. Stoner. "Management". (2nd ed.). USA: Prentice-Hall, Inc. 1986.
[9] Jean-Christophe Lebraud dkk. McKinsey, April 2012.

[10] Jeschke, Sabina, "Society 4.0" - (R)Evolution of Society?; RWTH Aachen University. 2014.

[11] Kanter, "The Change Masters"; London, George Allen and Unwin. 1983.

[12] Keuper, Frank, at.all "Disruption und Transformation Management: Digital Leadership - Digitales Mindset Digitale Strategie"; Springer Gabler. 2018.

[13] Kirkbride; Pau. "Globalization: The External Pressures", John Wiley \& Sons, Ltd. 2001.

[14] Lugwig Von Bertalanfy. "General System Theory: Foundations, Development, Applications". 1968.

[15] Mirfani, A. Muhtaram. "Manajemen Perubahan - Landasan Teoritik untuk Praktek Kepemimpinan Instusional Pendidikan"; Bandung: TP Sarana Panca Karya Nusa. 2009.

[16] Mirfani, A. Muhtaram. "Educational Leadership in The Era of Industrial Revolution 4.0: The Challenge of Change The Principalship Orientation; https://doi.org/10.2991/upiupsi18.2019.4.

[17] Nardello, M., Madsen, O., \& Møller, C. "The smart production laboratory: A learning factory for industry 4.0 concepts". CEUR Workshop, 1898.

[18] Orlosky at.all. "Educational Administration Today", Ohio: Bell \& Howell Company. 1984.

[19] Puncreobutr, Vichian. "Education 4.0: New Challenge of Learning"; St. Theresa Journal of Humanities and Social Sciences; Vol.2 No.2 July-December 2016.

[20] Tannock, Stuart. 'The problem of education-based discrimination', British Journal of Sociology of Education,29:5,439 - 449. 2008.

[21] Rothman, D. "A Tsunami of learners called Generation Z". Retrieved 2 July 2019, from http://www.mdle.net/Journal/A_Tsunami_of_Learners_Cal led_Generation_Z.pdf.

[22] Senge, Peter. "The Fifth Discipline; The Art And Practice Of The Learning Organization”. Random House. 2000.

[23] Stroiteleva, Tamara G. at.all. "Peculiarities and Problems of Formation of Industry 4.0 in Modern Russia (in Popkova, Elena G. (2019). Industry 4.0: Industrial Revolution of the 21st Century, p.145-153); Springer International Publishing AG, 2019.

Toffler, Alvin. "Powershift; Knowledge, Wealth and Violence at the Edge of the 21st Century"; Bantam Books.Senge, Peter (2000): The Fifth Discipline; The Art And Practice Of The Learning Organization. Random House. 1990. 